\title{
Group cognitive behavioral therapy for patients with generalized social anxiety disorder in Japan: outcomes at I-year follow up and outcome predictors
}

\author{
This article was published in the following Dove Press journal: \\ Neuropsychiatric Disease and Treatment \\ 19 February 2013 \\ Number of times this article has been viewed
}

\author{
Akiko Kawaguchi' \\ Norio Watanabe' \\ Yumi Nakano² \\ Sei Ogawa' \\ Masako Suzuki' \\ Masaki Kondo' \\ Toshi A Furukawa ${ }^{3}$ \\ Tatsuo Akechi' \\ 'Department of Psychiatry and \\ Cognitive-Behavioral Medicine, \\ Nagoya City University Graduate \\ School of Medical Sciences, Nagoya, \\ Japan; ${ }^{2}$ Sugiyama Jogakuen University \\ School of Human Sciences, Nisshin, \\ Japan; ${ }^{3}$ Department of Health \\ Promotion and Human Behavior, \\ Kyoto University Graduate School \\ of Medicine/School of Public Health, \\ Kyoto, Japan
}

Background: Social anxiety disorder (SAD) is one of the most common psychiatric disorders worldwide. Cognitive behavioral therapy (CBT) is an effective treatment option for patients with SAD. In the present study, we examined the efficacy of group CBT for patients with generalized SAD in Japan at 1-year follow-up and investigated predictors with regard to outcomes.

Methods: This study was conducted as a single-arm, naturalistic, follow-up study in a routine Japanese clinical setting. A total of 113 outpatients with generalized SAD participated in group CBT from July 2003 to August 2010 and were assessed at follow-ups for up to 1 year. Primary outcome was the total score on the Social Phobia Scale/Social Interaction Anxiety Scale (SPS/ SIAS) at 1 year. Possible baseline predictors were investigated using mixed-model analyses.

Results: Among the 113 patients, 70 completed the assessment at the 1-year follow-up. The SPS/SIAS scores showed significant improvement throughout the follow-ups for up to 1 year. The effect sizes of SPS/SIAS at the 1-year follow-up were 0.68 (95\% confidence interval $0.41-0.95) / 0.76(0.49-1.03)$ in the intention-to-treat group and $0.77(0.42-1.10) / 0.84(0.49-1.18)$ in completers. Older age at baseline, late onset, and lower severity of SAD were significantly associated with good outcomes as a result of mixed-model analyses.

Conclusions: CBT for patients with generalized SAD in Japan is effective for up to 1 year after treatment. The effect sizes were as large as those in previous studies conducted in Western countries. Older age at baseline, late onset, and lower severity of SAD were predictors for a good outcome from group CBT.

Keywords: social phobia, cognitive behavior therapy, psychotherapy

\section{Introduction}

Social anxiety disorder (SAD), often referred to as social phobia, is characterized by fear and avoidance of social situations. Epidemiological surveys have shown that $\mathrm{SAD}$ is the fourth most common psychiatric disorder, ${ }^{1}$ with a lifetime prevalence of $12 \%{ }^{2}$ SAD begins during adolescence and often persists. ${ }^{3}$ Patients with SAD often suffer from comorbid depression ${ }^{4,5}$ and other anxiety disorders. ${ }^{6}$ According to such characteristics of the disorder, SAD causes significant social dysfunction, and patients with SAD frequently develop functional impairment at work and in their private lives, which decreases their quality of life. ${ }^{7,8}$ Therefore, providing appropriate treatment for SAD is important.

Previous studies have provided evidence that pharmacotherapy, ${ }^{9}$ including benzodiazepines, selective serotonin-reuptake inhibitors, and monoamine oxidase inhibitors,
Correspondence: Norio Watanabe Department of Psychiatry and Cognitive-Behavioral Medicine, Nagoya City University Graduate School of Medical Sciences,

I Kawasumi, Mizuho-cho,

Mizuho-ku, Nagoya,

Aichi 467-860 I, Japan

Tel $+8 I 52853827$ I

Fax +8I 528520837

Email noriow@med.nagoya-cu.ac.jp 
are effective during SAD treatment as well as during cognitive behavioral therapy (CBT). ${ }^{10} \mathrm{~A}$ number of randomized controlled trials ${ }^{11,12}$ and strong evidence for a positive effect of CBT on SAD have been published. The effect size of CBT has been estimated at 0.71 (95\% confidence interval [CI] $0.56-0.85$ ) by a recent meta-analysis, ${ }^{13}$ and it showed lower relapse rates than treatments based on pharmacotherapy. ${ }^{14}$

Some researchers have demonstrated the effectiveness of CBT in a group format. Because patients with SAD are often anxious and avoid small-group work, they can be exposed to fearful situations by attending sessions. ${ }^{10}$ Furthermore, group CBT has greater cost-effectiveness compared with individual $\mathrm{CBT}{ }^{15}$

From 2003 onward, we conducted group CBT for outpatients with SAD at the Department of Psychiatry, Nagoya City University Hospital, based on previous studies. Our preliminary posttreatment data (from July 2003 to January 2007, $\mathrm{n}=57$ ) show that group CBT is acceptable. ${ }^{16}$ We have also published the long-term (1-year) effects on quality of $\operatorname{life}^{17}(n=57)$ and symptomatology ${ }^{18}(n=62)$ in patients with SAD. These studies examined the baseline predictors of the outcomes, but none were found. These studies ${ }^{16-18}$ also had limitations because of small sample size, and many dropout cases made it difficult to identify predictors. Furthermore, we included both the generalized and nongeneralized subtypes of SAD in these studies. Although both subtypes can be improved by CBT, the generalized subtype has more severe social anxiety symptoms and social function disability than those of the nongeneralized subtype, and patients are more impaired prior to and after treatment. ${ }^{19}$ Our previous studies may have contaminated efficacy by including both subtypes.

To overcome these limitations, in the present study we accumulated twice the number of participants $(n=113)$ as in our previous studies, ${ }^{16-18}$ and we focused on the generalized subtype to present more conclusive data. Moreover, we adopted a mixed-model analysis, which is considered the most effective way to identify treatment outcome predictors. Many studies have attempted to identify predictors of treatment outcomes, but only a few specific predictors have been found. ${ }^{20}$ Baseline predictors may enable us to provide CBT more effectively and to prevent dropout from treatment.

Furthermore, although CBT was originally developed in Western countries, some previous studies have discussed the cultural boundaries of SAD symptoms or SAD treatment. ${ }^{21,22}$ A condition called "taijin kyofusho" syndrome occurs in Japan and some other East Asian countries, as stated in the appendix of the Diagnostic and Statistical Manual of Mental Disorders (DSM-IV). From this perspective, exploring the efficacy of CBT for SAD has a significant meaning in Japan.

Thus, we conducted this study with the aim of identifying the long-term efficacy and predictors of group CBT for patients with generalized SAD in Japan.

\section{Methods}

\section{Subjects}

From July 2003 to August 2010, 113 outpatients with SAD were enrolled in the group-based CBT program at the Department of Psychiatry, Nagoya City University Hospital, Japan. All patients fulfilled the criteria for generalized SAD as the primary disorder according to the structured clinical interview for the DSM-IV. Furthermore, all patients met the following criteria: (1) no history of psychosis or bipolar disorder, or current substance-abuse disorder, (2) no previous CBT treatments, with agreement not to be involved in any other structured psychosocial therapies during treatment, and (3) absence of cluster B personality disorder. We included patients with current axis I disorders if symptoms were controlled sufficiently to allow joining a group session. For example, we included major depressive disorder or other current anxiety disorders or patients with axis II personality disorders except criterion (3).

All patients gave written informed consent after a full explanation of the study. This study was approved by the ethics committee of the Nagoya City University Graduate School of Medical Sciences.

\section{Treatments}

This study was conducted as a single-arm, naturalistic, follow-up study in a routine Japanese clinical setting. We followed the CBT manual for SAD written by Andrews et al, ${ }^{23}$ and we modified and improved the program according to Clark and Wells' model. ${ }^{24}$ Treatment was conducted in groups of three patients led by one principal therapist and one cotherapist, and were scheduled for 120 minutes once per week.

The average number of sessions was 14 (range 12-20), depending on the needs of each group. The program included (1) psychoeducation about SAD (session 1), (2) introduction about the individual cognitive behavioral model of SAD (session 2), (3) experiments to drop safety behavior and selffocused attention (from session 8 to last session), (4) attention training to shift focus away from themselves to the task or the external social situation (sessions 4 and 5), (5) video feedback of role-playing in anxious situations to modify their self-image (sessions 6 and 7), (6) in vivo exposure using behavioral experiments to test the patient's catastrophic 
predictions (from session 8 to last session), and (7) cognitive restructuring (session 3 , from session 8 to last session). We assigned homework to the patients after every session. Among 113 patients, 98 patients $(86.7 \%)$ completed CBT, and almost all of the patients $(n=109)$ finished all the exercise kinds, even when they were absent from a few sessions.

Eight therapists (five psychiatrists and three doctorallevel clinical psychologists), with more than 3 years of clinical practice with anxiety disorders, conducted the treatment program. Adherence to the treatment manual was monitored by group discussion once per month. We allowed patients to use antidepressants and benzodiazepines during CBT, because our study was based in a clinical setting and there is some evidence for combined pharmacologic/CBT therapy. ${ }^{11,25}$ Patients did not participate in any other structured psychotherapy while attending group CBT.

\section{Assessment}

The principal therapist conducted the mood- and anxietydisorder sections of the structured clinical interview for the DSM-IV at baseline, for the SAD diagnosis, and any mood and anxiety comorbidities.

Patients' demographic data were gathered at baseline, including such sociodemographic factors as sex, age, educational status, marital status, and employment status. Information about age of onset and duration of SAD, SAD subtype, psychiatric comorbidities, and medication use was also obtained.

The patients were assessed with self-report questionnaires at baseline, post-treatment, and by mail at the 1-year follow-up. Our primary outcome was the total Social Phobia Scale/Social Interaction Anxiety Scale (SPS/SIAS) ${ }^{26}$ score at the 1-year follow-up.

\section{SPS/SIAS}

The SPS and SIAS are 20-item self-report questionnaires with ratings on a 4-point scale from 0 (not at all characteristic or true of me) to 4 (extremely characteristic or true of me), and total scores of $0-80$. A high score indicates severe symptoms. The SPS measures the fear of being observed, whereas the SIAS provides a measure of fear of social interaction. Sufficient internal consistency, reliability, and discrimination, as well as predictive and concurrent validity have been demonstrated for both original and Japanese versions. ${ }^{27}$ Cronbach's alphas of our sample for SPS/SIAS were 0.88/0.60-0.88.

\section{Fear Questionnaire social phobia subscale}

The Fear Questionnaire social phobia subscale (FQ-sp) ${ }^{28}$ is a 5 -item self-reported instrument for measuring the fear-motivated avoidance of being observed, performing, being criticized, and talking to authorities. Items are rated on a 9-point Likert-type scale, from 0 (would not avoid it) to 8 (always avoid it). A high score indicates severe symptoms. Good test-retest reliability and factor validity have been demonstrated. ${ }^{29}$

\section{Statistical analyses}

We compared treatment completers with patients who dropped out using unpaired $t$-tests for continuous variables or chi-square tests for categorical variables. We also calculated Cohen's $d$ for the continuous variables. Treatment completers were defined as participants who had attended at least $80 \%$ of all treatment sessions and completed posttreatment and 1-year follow-up questionnaires.

The pretreatment and 1-year follow-up scores on SPS/ SIAS were compared using paired $t$-tests to quantify outcomes from the CBT program. Furthermore, to examine the outcomes of the CBT program across various aspects of the disorder, pre- and posttreatment scores were compared for SPS, SIAS, and FQ-sp using paired $t$-tests, and pretreatment and 1-year follow-up were compared for FQ-sp using paired $t$-tests. To show the magnitude of the treatment effect, we calculated the effect size ( $\mathrm{M}$ pretest $-\mathrm{M}$ posttest)/pooled standard deviation [SD]. All statistical analyses for these treatment outcomes were conducted twice: once based on the intention-to-treat (ITT) principle and once among the completers only. The ITT analyses were conducted using the last-observation-carried forward (LOCF) model, for which we used the mid-treatment data (after the eighth session) or the 3-month follow-up data, whichever were the last observational data available. We used the LOCF model to present more conservative treatment-effectiveness estimates.

We conducted mixed-model analyses to detect the baseline predictors of treatment outcome with the 1-year follow-up SPS/SIAS score as a dependent variable and the baseline demographic and clinical variables (sex, age, marital status, educational status, employment status, onset, duration of SAD, current mood disorder, current anxiety disorder, antidepressant use at baseline, benzodiazepine use at baseline, number of treatment sessions, severity) as variables. We converted continuous variables into categorical variables for this analysis. Age and onset of SAD age were categorized by Medline search criteria (age was divided into three categories: $13-18$ years, $19-45$ years, and $\geq 46$ years; onset of SAD was divided into three categories: $\leq 12$ years of age, 13-18 years of age, and 19-45 years of age). The number of treatment sessions was divided into 
Table I Demographic and diagnostic characteristics of the patients and a comparison of treatment completers and dropouts

\begin{tabular}{|c|c|c|c|c|}
\hline & Total & Dropout & Completers & $P$ value \\
\hline & 113 & 43 & 70 & \\
\hline \multicolumn{5}{|l|}{ Gender (\%) } \\
\hline Female & $56(49.6)$ & $19(44.2)$ & $37(0.53)$ & \multirow[t]{2}{*}{0.37} \\
\hline Male & $57(50.4)$ & $24(55.9)$ & $33(47.1)$ & \\
\hline Age Mean (SD) & $31.8(10.4)$ & $30.0(9.9)$ & $32.9(10.5)$ & 0.14 \\
\hline \multicolumn{5}{|l|}{ Education (\%) } \\
\hline University & $34(30.1)$ & $8(18.6)$ & $26(37.1)$ & \multirow[t]{4}{*}{0.10} \\
\hline College & $16(14.2)$ & $5(\mathrm{II} .7)$ & II (I5.7) & \\
\hline High school & $58(5 \mid .3)$ & $27(62.8)$ & $31(44.2)$ & \\
\hline Junior high school & $5(4.4)$ & $3(7.0)$ & $2(2.9)$ & \\
\hline \multicolumn{5}{|l|}{ Marital status (\%) } \\
\hline Married & $39(34.5)$ & $15(34.9)$ & $24(34.3)$ & \multirow[t]{3}{*}{0.99} \\
\hline Separated/divorced & $3(2.7)$ & I (2.3) & $2(2.9)$ & \\
\hline Single, never married & $71(62.8)$ & $27(62.8)$ & $44(62.9)$ & \\
\hline \multicolumn{5}{|l|}{ Employment (\%) } \\
\hline Full-time employment & $23(20.4)$ & $6(14.0)$ & $17(24.3)$ & \multirow[t]{4}{*}{0.07} \\
\hline Full-time student & $20(17.7)$ & $12(28.0)$ & $8(1 \mathrm{I} .4)$ & \\
\hline Part-time/homemaker/retired & $46(40.7)$ & $14(32.6)$ & $32(45.7)$ & \\
\hline Unemployed & $24(2 \mid .2)$ & II (25.6) & $13(18.6)$ & \\
\hline Onset of SAD, mean (SD) & $17.3(5.9)$ & I5.I (4.7) & $18.7(6.2)$ & $0.00 \mathrm{I}$ \\
\hline Duration of SAD, mean (SD) & $14.3(11.5)$ & $15.0(|| .4)$ & $13.8(\mid 1.6)$ & 0.62 \\
\hline Number of sessions taken, mean (SD) & $14.0(3.6)$ & $11.7(4.4)$ & I5.5 (I.8) & $<0.005$ \\
\hline Benzodiazepine use at baseline (\%) & $37(32.7)$ & II (25.6) & $26(37.1)$ & 0.2 \\
\hline Antidepressant use at baseline (\%) & $58(51.3)$ & $21(49.0)$ & $37(52.9)$ & 0.68 \\
\hline Current mood disorder (\%) & $27(23.9)$ & $12(10.6)$ & $15(13.3)$ & 0.5 \\
\hline Current anxiety disorder (\%) & II (9.7) & $4(3.5)$ & $7(6.2)$ & 1.0 \\
\hline FQ-sp score at baseline & $24.7(6.2)$ & $24.3(6.4)$ & $24.9(6.1)$ & 0.58 \\
\hline SPS total score at baseline & $37.8(14.4)$ & $43.2(15.2)$ & $34.4(12.8)$ & 0.002 \\
\hline SIAS total score at baseline & $56.0(12.5)$ & $57.8(13.9)$ & $54.8(11.6)$ & 0.24 \\
\hline
\end{tabular}

Abbreviations: FQ-sp, Fear Questionnaire social phobia subscale; ITT, intention-to-treat; SAD, social anxiety disorder; SIAS, Social Interaction Anxiety Scale; SPS, social phobia scale.

two categories according to our definition of minimal session number $(\mathrm{n}=12)$. We divided the variable of duration of SAD into two categories of $\leq 1$ year or $>1$ year, because we wanted to explore the effectiveness of early treatment intervention. Baseline severity of SAD was defined by the baseline SPS total score, based on Heimberg et al, ${ }^{30}$ with more than 34 being defined as severe.

All the statistical tests were two-tailed, and an alpha value of less than 0.05 was considered statistically significant. All the data were examined using SPSS 19.0 (IBM, Armonk, NY, USA) for Windows.

\section{Results}

Demographic and diagnostic characteristics of patients and comparison of treatment completers and dropouts

One hundred and thirteen outpatients with SAD (57 males and 56 females; age range 14-63 years; mean \pm SD $31.8 \pm$ 10.4 years) were enrolled in our study. Table 1 summarizes the

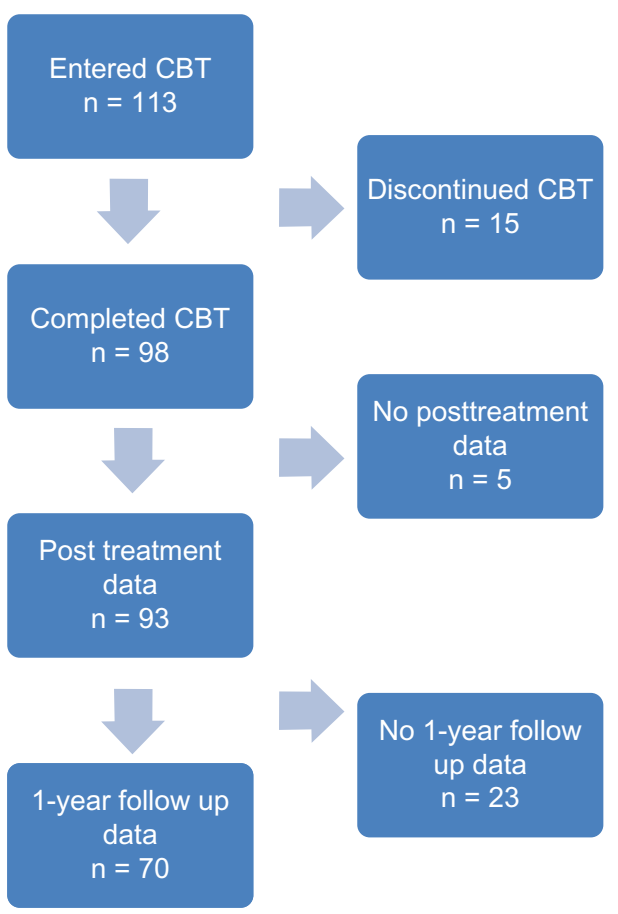

Figure I Number of patients at different time points. Abbreviation: $\mathrm{CBT}$, cognitive behavioral therapy. 
Table 2 ITT and completers mean symptom scores and SDs at the pre- and post-treatment

\begin{tabular}{|c|c|c|c|c|c|c|}
\hline \multirow[t]{2}{*}{ Mean (SD) } & \multicolumn{3}{|c|}{ ITT $(\mathbf{N}=113)$} & \multicolumn{3}{|c|}{ Completers $(\mathrm{N}=70)$} \\
\hline & Pre & Post & $P$ value & Pre & Post & $P$ value \\
\hline FQ-sp score & $24.6(6.3)$ & $19.6(8.6)$ & $<0.05$ & $24.9(6.1)$ & 19.1 (8.2) & $<0.05$ \\
\hline SPS total score & $37.8(14.4)$ & $28.1(15.7)$ & $<0.05$ & $34.4(12.8)$ & $24.6(13.0)$ & $<0.05$ \\
\hline SIAS total score & $56.0(12.5)$ & $45.4(15.2)$ & $<0.05$ & $54.8(11.6)$ & $44.6(13.5)$ & $<0.05$ \\
\hline
\end{tabular}

Abbreviations: FQ-sp, Fear Questionnaire social phobia subscale; ITT, intention-to-treat; SIAS, Social Interaction Anxiety Scale; SPS, social phobia scale.

demographic and clinical characteristics of the patients and compares treatment completers with dropouts. All participants met the principal diagnostic criteria for the DSM-IV SAD generalized subtype.

As a result of chi-square tests for categorical variables, onset of SAD and SPS total score at baseline showed $P<0.05$, but no other major differences were observed between completers and dropouts. The number of sessions taken by patients on average was 14 (range 12-20).

Figure 1 shows the number of patients at different time points. Of the 113 patients who were enrolled, 98 completed treatment and 70 finished the 1-year follow-up. Although pre- and posttreatment SPS were not normally distributed, we conducted analyses as we planned, because the other measures were normally distributed.

\section{Changes in symptoms and function through treatment}

Table 2 shows the mean symptom scores and SDs of all measures for all participants (ITT population using the LOCF model) and pre- and posttreatment completers and pre- and 1-year follow-ups. An examination of the change in symptom measures (SPS, SIAS, and FQ-sp) between pre- and posttreatment and between pre- and 1 -year follow-ups revealed significant improvements not only for the completers but also for the ITT samples (all $P<0.05)$.

Next, the effect sizes for each symptom measure were calculated, and the results are presented in Tables 4 and 5 . The effect sizes for the total SPS/SIAS scores at the 1-year follow-up, which was our primary outcome, were 0.68
(95\% CI $0.41-0.95) / 0.76$ (95\% CI, 0.49-1.03) in the ITT sample and $0.77(0.42-1.10) / 0.84(0.49-1.18)$ in completers. Based on the ITT sample analyses, effect sizes for assessment at posttreatment were SPS $0.64(0.37-0.90)$, SIAS 0.76 (0.49-1.03), and FQ-sp $0.66(0.39-0.93)$, and at 1-year follow-up FQ-sp was 0.76 (0.48-1.02).

Effect sizes for treatment completers at posttreatment were SPS 0.81 (95\% CI, 0.46-1.15), SIAS 0.76 (0.49-1.10), and FQ-sp 0.81 (0.47-1.15), and the effect size of the FQ-sp at 1-year follow up was $0.96(0.61-1.31)$, indicating a greater change than that in the ITT sample.

All effect sizes were larger at 1-year follow-up than those at posttreatment.

\section{Predictors of treatment outcomes at I-year follow-up}

Table 6 summarizes the mixed-model analyses outcome. A significant difference was found for SIAS in the older age-group at baseline ( $P=0.019)$, a lower severity on SPS $(P=0.000)$, and late onset of SAD for both SPS $(P=0.001)$ and SIAS $(P=0.000)$ as predictors of good treatment outcome.

\section{Discussion \\ Main findings}

The results indicate the long-term efficacy of a CBT program for Japanese patients with SAD generalized subtype. Although we focused on patients with the generalized subtype, who have more severe symptoms than those with the nongeneralized subtype, the effect sizes were as large as those in a meta-analysis conducted in Western countries ${ }^{13}$ and our previous study at posttreatment.

Table 3 ITT and completers mean symptom scores and SDs at the pre-treatment and I-year follow ups

\begin{tabular}{|c|c|c|c|c|c|c|}
\hline \multirow[t]{2}{*}{ Mean (SD) } & \multicolumn{3}{|c|}{ ITT $(\mathbf{N}=1 \mid 3)$} & \multicolumn{3}{|c|}{ Completers $(\mathbf{N}=\mathbf{7 0})$} \\
\hline & Pre & I-year & $P$ value & Pre & I-year & $P$ value \\
\hline FQ-sp score & $24.6(6.3)$ & $19.2(7.9)$ & $<0.05$ & $24.9(6.1)$ & I8.3 (7.7) & $<0.05$ \\
\hline SPS total score & $37.5(14.4)$ & $27.3(16.1)$ & $<0.05$ & $34.4(12.8)$ & $24.1(14.1)$ & $<0.05$ \\
\hline SIAS total score & $56.0(12.5)$ & $45.4(15.2)$ & $<0.05$ & $54.8(11.6)$ & 43.7 (I4.9) & $<0.05$ \\
\hline
\end{tabular}

Abbreviations: FQ-sp, Fear Questionnaire social phobia subscale; ITT, intention-to-treat; SIAS, Social Interaction Anxiety Scale; SPS, social phobia scale. 
Table 4 Effect sizes for ITT and completers at the pre- and post-treatment compared with our previous study

\begin{tabular}{|c|c|c|c|c|}
\hline & $\begin{array}{l}\text { ITT } \\
(\mathbf{N}=|| 3)\end{array}$ & $\begin{array}{l}\text { Previous study } \\
\text { ITT }(\mathbf{N}=\mathbf{5 7})\end{array}$ & $\begin{array}{l}\text { Completers } \\
(\mathbf{N}=\mathbf{7 0})\end{array}$ & $\begin{array}{l}\text { Previous study } \\
\text { completers } \\
(\mathbf{N}=\mathbf{5 0})\end{array}$ \\
\hline FQ-sp score & 0.66 & 1.01 & 0.81 & 1.19 \\
\hline$(95 \% \mathrm{Cl})$ & $(0.39-0.93)$ & & $(0.46-1.15)$ & \\
\hline SPS total score & 0.64 & 0.75 & 0.76 & 0.83 \\
\hline$(95 \% \mathrm{Cl})$ & $(0.37-0.90)$ & & $(0.4 I-I . I 0)$ & \\
\hline SIAS total score & 0.76 & 0.79 & 0.81 & 0.89 \\
\hline$(95 \% \mathrm{Cl})$ & $(0.49-1.03)$ & & $(0.47-I .15)$ & \\
\hline
\end{tabular}

Abbreviations: FQ-sp, Fear Questionnaire social phobia subscale; ITT, intention-to-treat; SIAS, Social Interaction Anxiety Scale; SPS, social phobia scale.

According to the effect-size calculation, our treatment program had significant effects at posttreatment that were maintained until the 1-year follow-up. This outcome is the same as that of a previous study, which demonstrated the maintenance efficacy of $\mathrm{CBT}^{14}$ and indicates the possibility that patients are able to use treatment elements by themselves after group treatment.

Few CBT therapists are available for SAD treatment in Japan, and national health insurance does not include CBT for anxiety disorders. Thus, accumulating evidence for a positive effect of CBT in Japan is a matter of urgency, and we hope our study contributes to this purpose. Group CBT is more cost-effective than individual CBT in this regard, and we would like to diffuse this effective treatment for SAD in Japan.

We investigated baseline predictors for treatment outcomes. A number of studies have examined the role of particular variables in predicting the response to treatment; however, results have been inconsistent and inconclusive..$^{20}$ The severity of comorbid depression, ${ }^{31,32}$ symptomatic severity, ${ }^{31}$ avoidant personality disorder, ${ }^{33}$ and expectancy ${ }^{32}$ have been suggested as possible follow-up predictors for group CBT.

Although some demographic variables (female, married, higher education) were possible follow-up predictors in a study ${ }^{34}$ that conducted individual CBT, and the aforementioned demographic variables were not statistically significant in our group CBT study, we believe that suitable characteristics of patients are different between group CBT and individual therapy.

We found that older age, late onset of SAD, and less severe symptoms on SPS were possible baseline treatment predictors for a good outcome. These results agreed with our clinical impression. We may have to pay more attention to patients who are contrary to those features by reflecting on those results.

Future studies should focus not only on pretreatment variables but also on the treatment process, such as homework compliance and the client-therapist relationship, as suggested by Scholing and Emmelkamp. ${ }^{31}$ These factors may help improve the clinical practice of CBT for SAD.

\section{Limitations}

The present study had several limitations. First, this study was conducted in a routine Japanese clinical setting as a single-arm, naturalistic, follow-up study. Thus, a random control trial is needed to estimate the conservative efficacy of treatment.

Second, antidepressant and benzodiazepine medications were allowed during treatment, but information about the amount of drug consumption during the course was not collected. We are unable to consider dose effects of medications on CBT; however, use of medication at baseline was not a significant predictor of treatment outcomes in the present study.

Third, some may argue that there were no patients with avoidant personality disorder in our study. We used the structured clinical interview of the DSM-IV mood/anxiety module, but we did not use other modules considering patient load. We only excluded patients who were clinically diagnosed with personality B disorders in accordance with group therapy. The diagnosis of avoidance personality disorder is difficult, as is distinguishing between severe generalized SAD and avoidant personality disorder, thus we

Table 5 Effect sizes for ITT and completers at the pre-treatment and I-year follow ups

\begin{tabular}{lll}
\hline & ITT $(\mathbf{N}=I \mid 3)$ & Completers $(\mathbf{N}=\mathbf{7 0})$ \\
\hline FQ-sp score & 0.76 & 0.96 \\
$(95 \% \mathrm{Cl})$ & $(0.48-1.02)$ & $(0.6 \mathrm{I}-\mathrm{I.31})$ \\
SPS total score & 0.68 & 0.77 \\
$(95 \% \mathrm{Cl})$ & $(0.41-0.95)$ & $(0.42-1.10)$ \\
SIAS total score & 0.76 & 0.84 \\
$(95 \% \mathrm{Cl})$ & $(0.49-1.03)$ & $(0.49-1.18)$ \\
\hline
\end{tabular}

Abbreviations: FQ-sp, Fear Questionnaire social phobia subscale; ITT, intentionto-treat; SIAS, Social Interaction Anxiety Scale; SPS, social phobia scale. 
Table 6 The mixed model analyses outcome for detecting the baseline predictors of the SPS and SIAS scores at the I-year follow ups

\begin{tabular}{|c|c|c|c|c|c|c|c|}
\hline & \multirow[t]{2}{*}{$\mathbf{N}$} & \multicolumn{3}{|l|}{ SPS } & \multicolumn{3}{|l|}{ SIAS } \\
\hline & & Mean & SE & $P$ & Mean & SE & $P$ \\
\hline \multicolumn{8}{|l|}{ Gender } \\
\hline Female & 56 & 28.4 & 1.8 & 0.296 & 47.1 & 1.7 & 0.38 \\
\hline Male & 57 & 31.0 & 1.8 & & 49.2 & 1.7 & \\
\hline \multicolumn{8}{|l|}{ Age } \\
\hline $13-18$ & 7 & 30.3 & 5.1 & 0.087 & 45.0 & 4.7 & $0.019 \ddagger$ \\
\hline $19-45$ & 91 & 30.7 & 1.4 & & 49.6 & 1.3 & \\
\hline$\geq 46$ & 15 & 22.7 & 3.3 & & 40.3 & 3.1 & \\
\hline \multicolumn{8}{|l|}{ Educational status } \\
\hline University & 34 & 27.5 & 2.2 & 0.68 & 50.1 & 2.1 & 0.643 \\
\hline College & 16 & 29.6 & 3.3 & & 48.6 & 3.1 & \\
\hline High School & 58 & 30.5 & 1.8 & & 46.7 & 1.7 & \\
\hline Junior high school & 5 & 33.2 & 6.1 & & 47.4 & 5.8 & \\
\hline \multicolumn{8}{|l|}{ Marital status } \\
\hline Married & 39 & 28.4 & 2.2 & 0.740 & 45.5 & 2.0 & 0.223 \\
\hline Separated/divorced & 3 & 32.2 & 7.7 & & 45.4 & 7.2 & \\
\hline Single/never married & 71 & 30.3 & 1.6 & & 49.7 & 1.5 & \\
\hline \multicolumn{8}{|l|}{ Employment status } \\
\hline Full-time employment & 23 & 27.5 & 2.7 & 0.39 & 49.0 & 2.6 & 0.769 \\
\hline Full-time student & 20 & 32.9 & 3.0 & & 48.1 & 2.9 & \\
\hline Part-time/homemaker/retired & 46 & 28.2 & 1.9 & & 46.8 & 1.8 & \\
\hline Unemployed & 24 & 32.0 & 2.7 & & 50.0 & 2.6 & \\
\hline \multicolumn{8}{|l|}{ Onset of SAD } \\
\hline$\leq 12$ & 17 & 40.0 & 3.1 & $0.001 *$ & 60.3 & 2.8 & $<0.0005^{*}$ \\
\hline $13-18$ & 65 & 26.9 & 1.7 & & 46.1 & 1.5 & \\
\hline $19-45$ & 28 & 29.2 & 2.1 & & 44.5 & 1.9 & \\
\hline \multicolumn{8}{|l|}{ Duration of SAD } \\
\hline$\leq 1$ & 6 & 23.0 & 5.5 & 0.216 & 39.2 & 5.1 & 0.089 \\
\hline $\mathrm{I}<$ & 104 & 30.0 & 1.3 & & 48.2 & 1.2 & \\
\hline \multicolumn{8}{|l|}{ Number of sessions } \\
\hline$<12$ & 18 & 33.3 & 3.8 & 0.338 & 51.5 & 3.6 & $0.34 I$ \\
\hline $12 \leq$ & 95 & 29.5 & 1.3 & & 47.9 & 1.3 & \\
\hline \multicolumn{8}{|l|}{ Benzodiazepine use } \\
\hline No & 76 & 30.3 & 1.5 & 0.521 & 49.7 & $\mathrm{I} .4$ & 0.059 \\
\hline Yes & 37 & 28.6 & 2.2 & & 45.0 & 2.0 & \\
\hline \multicolumn{8}{|l|}{ Antidepressant use } \\
\hline No & 60 & 29.2 & 1.8 & 0.705 & 48.6 & 1.7 & 0.716 \\
\hline Yes & 58 & 30.1 & 1.7 & & 47.7 & 1.6 & \\
\hline \multicolumn{8}{|l|}{ Current mood disorder } \\
\hline No & 86 & 30.0 & $\mathrm{I} .4$ & 0.775 & 47.1 & 1.3 & 0.106 \\
\hline Yes & 27 & 29.1 & 2.6 & & 51.5 & 2.4 & \\
\hline \multicolumn{8}{|l|}{ Current anxiety disorder } \\
\hline No & 102 & 29.1 & 1.3 & 0.121 & 47.4 & 1.2 & 0.067 \\
\hline Yes & 11 & 35.6 & 3.9 & & 54.6 & 23.7 & \\
\hline \multicolumn{8}{|l|}{ Severity } \\
\hline $\mathrm{SPS} \leq 33$ & 48 & 21.4 & 1.6 & $<0.0005^{*}$ & 46.1 & 1.8 & 0.151 \\
\hline $\mathrm{SPS} \geq 34$ & 65 & 35.6 & 1.4 & & 49.5 & 1.5 & \\
\hline
\end{tabular}

Note: $* P<0.05$.

Abbreviations: SAD, social anxiety disorder; SE, standard error; SPS, Social Phobia Scale.

did not diagnose avoidant personality disorder rigidly in the aforementioned way.

Fourth, there were some statistical issues in our study. Multiple $t$-tests may have increased the risk for type I errors. However, the magnitude of the treatment effectiveness was quantified by effect size as well as the percentage reduction. Besides, data for pre- and posttreatment SPS were not normally distributed, although those for the other measures were normally distributed. This might have had some effect on the statistical validity of our study. However, we conducted 
post hoc Mann-Whitney analysis between completers and dropouts, and the result was not different.

Some may point out that we did not use the Liebowitz Social Anxiety Scale as the primary outcome, which is a widely used measure. Because this study was conducted as routine Japanese clinical work, follow-up assessments done by post- and self-reporting versions of this ${ }^{35}$ have not been validated in Japan to date.

Moreover, a recent study ${ }^{36}$ showed the effectiveness of attention training, which costs less than typical CBT. Although our program included attention training, we might be able to improve our program by emphasizing this component, according to the new findings.

Despite these limitations, this study provided evidence of long-term efficacy of group CBT for Japanese patients with generalized SAD. Although there is still room for improvement, our results favor the use of CBT for generalized SAD in Japan.

\section{Conclusions}

Group CBT resulted in improvements in Japanese patients with generalized SAD, and these improvements were maintained for up to 1 year after group CBT. We showed that older age at baseline, late onset, and lower severity of SAD were predictors of good outcome at 1-year follow-up for group CBT.

\section{Acknowledgments}

This study was supported by the Department of Psychiatry and Cognitive-Behavioral Medicine, Nagoya City University Graduate School of Medical Sciences, and also by a Grant-inAid for Scientific Research (No. 10103220) from the Ministry of Health, Labour and Welfare, Japan.

\section{Disclosure}

The authors declare that they have no competing interests with regard to the present study.

\section{References}

1. Liebowitz MR, Heimberg RG, Fresco DM, Travers J, Stein MB. Social phobia or social anxiety disorder: what's in a name? Arch Gen Psychiatry. 2000;57(2):191-192.

2. Kessler RC, Berglund P, Demler O, Jin R, Merikangas KR, Walters EE. Lifetime prevalence and age-of-onset distributions of DSM-IV disorders in the National Comorbidity Survey Replication. Arch Gen Psychiatry. 2005;62(6):593-602.

3. Keller MB. The lifelong course of social anxiety disorder: a clinical perspective. Acta Psychiatr Scand Suppl. 2003;(417):85-94.

4. Beesdo K, Bittner A, Pine DS, et al. Incidence of social anxiety disorder and the consistent risk for secondary depression in the first three decades of life. Arch Gen Psychiatry. 2007;64(8):903-912.
5. Kessler RC, Stang P, Wittchen HU, Stein M, Walters EE. Lifetime co-morbidities between social phobia and mood disorders in the US National Comorbidity Survey. Psychol Med. 1999;29(3):555-567.

6. Chartier MJ, Walker JR, Stein MB. Considering comorbidity in social phobia. Soc Psychiatry Psychiatr Epidemiol. 2003;38(12):728-734.

7. Kessler RC. The impairments caused by social phobia in the general population: implications for intervention. Acta Psychiatr Scand Suppl. 2003;(417):19-27.

8. Davidson JR, Hughes DL, George LK, Blazer DG. The epidemiology of social phobia: findings from the Duke Epidemiological Catchment Area Study. Psychol Med. 1993;23(3):709-718.

9. Blanco C, Schneier FR, Schmidt A, et al. Pharmacological treatment of social anxiety disorder: a meta-analysis. Depress Anxiety. 2003; 18(1):29-40.

10. Heimberg RG. Cognitive-behavioral therapy for social anxiety disorder: current status and future directions. Biol Psychiatry. 2002;51(1): 101-108.

11. Davidson JR, Foa EB, Huppert JD, et al. Fluoxetine, comprehensive cognitive behavioral therapy, and placebo in generalized social phobia. Arch Gen Psychiatry. 2004;61(10):1005-1013.

12. Hofmann SG. Cognitive mediation of treatment change in social phobia. J Consult Clin Psychol. 2004;72(3):393-399.

13. Acarturk C, Cuijpers P, van Straten A, de Graaf R. Psychological treatment of social anxiety disorder: a meta-analysis. Psychol Med. 2009;39(2):241-254.

14. Liebowitz MR, Heimberg RG, Schneier FR, et al. Cognitive-behavioral group therapy versus phenelzine in social phobia: long-term outcome. Depress Anxiety. 1999;10(3):89-98.

15. Gould RA, Buckminster S, Pollack MH, Otto MW, Massachusetts LY. Cognitive-behavioral and pharmacological treatment for social phobia: a meta-analysis. Clin Psychol (New York). 1997;4(4):291-306.

16. Chen J, Nakano Y, Ietzugu T, et al. Group cognitive behavior therapy for Japanese patients with social anxiety disorder: preliminary outcomes and their predictors. BMC Psychiatry. 2007;7:69.

17. Watanabe N, Furukawa TA, Chen J, et al. Change in quality of life and their predictors in the long-term follow-up after group cognitive behavioral therapy for social anxiety disorder: a prospective cohort study. BMC Psychiatry. 2010;10:81.

18. Furukawa TA, Nakano Y, Funayama T, et al. CBT modifies the naturalistic course of social anxiety disorder: Findings from an ABA design study in the routine clinical practices. Psychiatry Clin Neurosci. 2013. In press.

19. Brown EJ, Heimberg RG, Juster HR. Social phobia subtype and avoidant personality disorder: effect on severity of social phobia, impairment, and outcome of cognitive-behavioral treatment. Behav Ther. 1995;26(3):467-486.

20. Eskildsen A, Hougaard E, Rosenberg NK. Pre-treatment patient variables as predictors of drop-out and treatment outcome in cognitive behavioural therapy for social phobia: a systematic review. Nord $J$ Psychiatry. 2010;64(2):94-105.

21. Heimberg RG, Makris GS, Juster HR, Ost LG, Rapee RM. Social phobia: a preliminary cross-national comparison. Depress Anxiety. 1997;5(3):130-133.

22. Weissman MM, Bland RC, Canino GJ, et al. The cross-national epidemiology of social phobia: a preliminary report. Int Clin Psychopharmacol. 1996;11 Suppl 3:9-14.

23. Andrews G, Creamer M, Crino R, Hunt C, Lampe L, Page A. The Treatment of Anxiety Disorders: Clinician Guides and Patient Manuals. Cambridge: Cambridge University Press; 2002.

24. Clark D, Wells A. A cognitive model of social phobia. In: Heimberg RG, Liebowitz M, Hope DA, Schneier FR, editors. Social Phobia: Diagnosis, Assessment, and Treatment. New York: Guilford Press; 1995:69-93.

25. Blomhoff S, Haug TT, Hellström K, et al. Randomised controlled general practice trial of sertraline, exposure therapy and combined treatment in generalised social phobia. Br J Psychiatry. 2001;179:23-30. 
26. Mattick RP, Clarke JC. Development and validation of measures of social phobia scrutiny fear and social interaction anxiety. Behav Res Ther. 1998;36(4):455-470.

27. Kanai Y, Sasakawa S, Chen J, Suzuki S, Shimada H, Sakano Y. Development and validation of the Japanese version of Social Phobia Scale and Social Interaction Anxiety Scale. Jpn J Psychosom Med. 2004;44(11):841-850.

28. Marks IM. Behavioural Psychotherapy: Maudsley Pocket Book of Clinical Management. Bristol: John Wright; 1986.

29. Marks IM, Mathews AM. Brief standard self-rating for phobic patients. Behav Res Ther. 1979;17(3):263-267.

30. Heimberg RG, Mueller GP, Holt CS, Hope DA, Liebowitz MR. Assessment of anxiety in social interaction and being observed by others: the Social Interaction Anxiety Scale and the Social Phobia Scale. Behav Ther. 1992;23(1):53-73.

31. Scholing A, Emmelkamp PM. Prediction of treatment outcome in social phobia: a cross-validation. Behav Res Ther. 1999;37(7):659-670.
32. Chambless DL, Tran GQ, Glass CR. Predictors of response to cognitivebehavioral group therapy for social phobia. J Anxiety Disord. 1997; 11(3):221-240.

33. Feske U, Perry K, Chambless D, Renneberg B, Goldstein A. Avoidant personality disorder as a predictor for severity and treatment outcome among generalized social phobics. J Pers Disord. 1996;10:174-184.

34. Lincoln TM, Riefa W, Hahlwegb K, et al. Who comes, who stays, who profits? Predicting refusal, dropout, success, and relapse in a short intervention for social phobia. Psychother Res. 2005;15(3):210-225.

35. Fresco DM, Coles ME, Heimberg RG, et al. The Liebowitz Social Anxiety Scale: a comparison of the psychometric properties of selfreport and clinician-administered formats. Psychol Med. 2001;31(6): 1025-1035.

36. Heeren A, Reese HE, McNally RJ, Philippot P. Attention training toward and away from threat in social phobia: effects on subjective, behavioral, and physiological measures of anxiety. Behav Res Ther. 2012;50(1):30-39.
Neuropsychiatric Disease and Treatment

\section{Publish your work in this journal}

Neuropsychiatric Disease and Treatment is an international, peerreviewed journal of clinical therapeutics and pharmacology focusing on concise rapid reporting of clinical or pre-clinical studies on a range of neuropsychiatric and neurological disorders. This journal is indexed on PubMed Central, the 'PsycINFO' database and CAS.

\section{Dovepress}

The manuscript management system is completely online and includes a very quick and fair peer-review system, which is all easy to use. Visit http://www.dovepress.com/testimonials.php to read real quotes from published authors. 